\title{
Influence of Initial Value of Transient Time Step on Numerical Simulation of Blow Molding Balloon
}

\author{
Jinyao Bian*, Guobao Jin, Peng Qin, Guanghui Dai \\ School of Mechanical Engineering, Chaohu University, Hefei, China \\ Email: *bjysky@sina.com
}

How to cite this paper: Bian, J.Y., Jin, G.B., Qin, P. and Dai, G.H. (2020) Influence of Initial Value of Transient Time Step on Numerical Simulation of Blow Molding Balloon. American Journal of Computational Mathematics, 10, 266-274.

https://doi.org/10.4236/ajcm.2020.102014

Received: May 12, 2020

Accepted: June 20, 2020

Published: June 23, 2020

Copyright $\odot 2020$ by author(s) and Scientific Research Publishing Inc. This work is licensed under the Creative Commons Attribution International License (CC BY 4.0).

http://creativecommons.org/licenses/by/4.0/

\begin{abstract}
The correlation between the initial time value of transient iterative parameters and the blowing pressure in the numerical simulation process of blowing balloon is investigated by POLYFLOW. The results show that: 1) As the blow molding pressure increases, the boundary value of the iterative time step decreases rapidly at first and then slowly. At the end of the first step of iterative calculation for each boundary value, the balloon parison is in the mold core cavity. 2) If the initial time value of transient iterative parameters is smaller than the boundary value of the iterative time step, the balloon parison is still in the mold core cavity at the end of the first iteration. However, if the iterative calculation continues, the calculation process may be interrupted when the time step is smaller than the initial time value of the transient iterative parameters, which makes the blow molding simulation of balloon unable to continue. 3 ) It is suggested that the initial time value of transient iterative parameters is one order of magnitude smaller than the boundary value of the iterative time step to complete smoothly the simulation of blow molding balloon.
\end{abstract}

\section{Keywords}

Transient Iteration, Time-Step, Initial Time Value, Balloon Forming, Blow Molding Pressure

\section{Introduction}

To form the balloon, which is an important part of the balloon dilating catheter, various numerical methods are employed. Fu et al. used the MSC. Marc to conduct isothermal numerical simulation of the primary and secondary stretching processes of single-cavity balloon made of Polyamide 12, and the influence of 
stretching velocity on balloon wall thickness is analyzed [1]. Menary et al. used ABAQUS to simulate the molding process of nylon tube balloon with a diameter of $3 \mathrm{~mm}$ [2]. As the balloon molding method belongs to a blow molding method, POLYFLOW can be applied to the numerical simulation of balloon molding. However, POLYFLOW, as an important numerical technique, is rarely reported in balloon forming study.

POLYFLOW is widely used in the design of extrusion [3]-[9], thermal forming [10] [11], blow molding [12] [13] and other processes. Gupta S et al. [12] has carried out simulations of a $2 \mathrm{D}$ axisymmetric bottle blow molding using ANSYS POLYFLOW. The preform was made by extrusion and forced between two halves by pressurisation. Suraya S. et al. [13] simulated the blowing process of two dimensional model of a PP bottle using ANSYS POLYFLOW to predict the wall thickness distribution at four different parison's diameter: $8 \mathrm{~mm}, 10 \mathrm{~mm}, 18$ $\mathrm{mm}$, and $20 \mathrm{~mm}$. When POLYFLOW is adopted for design, it not only reduces the consumption of energy and raw materials but also makes the manufacturing process more economical and efficient than the traditional balloon forming [14].

In this work, POLYFLOW is employed to simulate the molding process of single balloon. The correlations between the initial value of transient time step and the pressure of balloon blow molding are studied, which is expected to provide useful suggestion for the choice of the initial time step.

\section{Theory and Equations}

In order to define boundary conditions for contact detection, a distinction must be established between regions where contact has occurred and regions of the free surface where contact has not yet been detected [14].

A normal force can be applied on an internal free surface to take the inflation into account. The displacement of the free surface can be described by the following dynamic and kinematic conditions prior to contact. The normal force $\boldsymbol{f}$ must be equal to zero, or more generally, be prescribed a given value $\boldsymbol{g}$.

$$
\boldsymbol{f}=\boldsymbol{g}
$$

where $\boldsymbol{g}$ is nonzero when an external force is applied on the free surface.

In the case of a steady-state problem, the normal velocity must be equal to zero because no mass crosses the free surface.

$$
\boldsymbol{v} \cdot \boldsymbol{n}=0
$$

where $\boldsymbol{v}$ is the velocity vector and $\boldsymbol{n}$ is the normal vector to the free surface.

Once contact occurs, it is impossible for the free surface to displace in the direction normal to the mold surface, and the velocity of the fluid becomes identical to that of the mold. At the same time, the force condition that was previously prescribed is replaced by an essential condition on the velocity in the tangential direction.

Once a solid domain is slightly penetrated by a node, a penalty term can be used to modify the discrete momentum equation of the node. In order to model the physics accurately, the penalty term can be different in the normal and tan- 
gential directions.

In the normal direction, the condition that the fluid velocity must be equal to the wall velocity is enforced with the penalty coefficient $k$.

$$
f_{n}=-k\left(\boldsymbol{v}-\boldsymbol{v}_{\text {wall }}\right) \boldsymbol{n}
$$

The default value of $k$ in POLYDATA is $10^{9}$, which is appropriate for most cases. When the contact detection is modeled, the time-marching parameters must be modified.

In the tangential direction, the velocity is prescribed through a linear law of the "slip" type, given by

$$
f_{s}=-F_{\text {slip }}\left(\boldsymbol{v}_{s}-\boldsymbol{v}_{s, \text { wall }}\right)
$$

where $F_{\text {slip }}$ is the slip coefficient. The default value of $F_{\text {slip }}$ in POLYDATA is $10^{9}$, which usually corresponds to a condition of zero relative velocity in the tangential direction.

\section{Calculation Model}

\subsection{Geometric Model and Mesh Generation}

The geometric model of balloon blow molding simulation is shown in Figure 1. The length of the mold core cavity is $L 15.0 \mathrm{~mm}$ and the maximum inner diameter of the mold core cavity is $D 7.0 \mathrm{~mm}$. The inner and outer diameters of the parison are $r 1.0 \mathrm{~mm}$ and $R 1.25 \mathrm{~mm}$, respectively. Here, the straight plastic tube is used as the balloon parison.

The geometric model in Figure 1 is meshed by GAMBIT, and result is shown in Figure 2. The interval sizes of mold mesh and balloon parison spacing are 0.1 $\mathrm{mm}$ and $0.05 \mathrm{~mm}$, respectively.

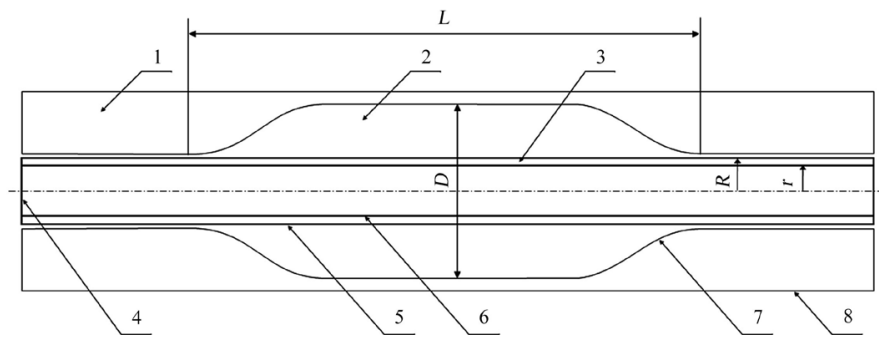

Figure 1. Geometric model for balloon blow molding simulation. 1. Mold core; 2. Balloon cavity; 3. Balloon parison; 4. End face of parison; 5. Outer wall of parison; 6. Inner wall of parison; 7. Inner wall of mold core; 8. Outerwall of mold core.
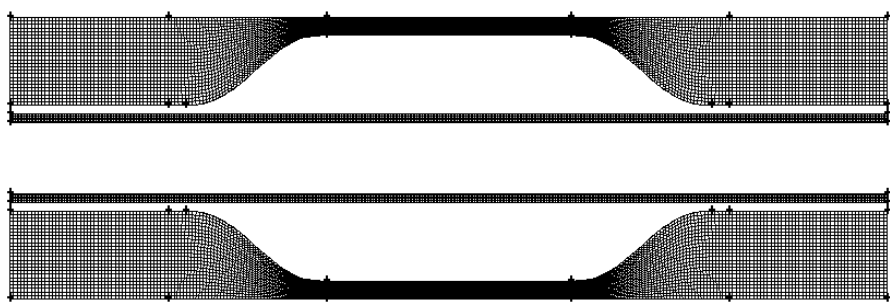

Figure 2. Mesh of the initial state of balloon blow molding simulation. 


\subsection{Boundary Conditions}

Calculation parameters are set in POLYDATA when the mesh file is imported. The boundary conditions are as follows. The mold core is a solid and the balloon parison is fluid. The inner wall of the parison is free boundary, which bears blow molding pressure. The outer wall of parison and the inner wall of mold core are the contact boundaries. The normal velocity and the tangential force on the end faces of parison are 0 .

\section{Initial Time Value of Transient Iterative Parameters}

Under a given blow molding pressure $P_{b}$, the boundary value of the initial time value of transient iterative parameters $t_{i}$ is studied by judging the location of parison at the end of the first iterative time step. Different boundary values of the initial time of transient iterative parameters can be obtained by changing $P_{b}$.

\subsection{Normal Molding Result}

When $t_{i}$ is reasonably set, the blow molding process of a balloon is carried out by POLYFLOW, then the normal blow molding result of a balloon can be obtained, as shown in Figure 3.

\subsection{Abnormal Molding Phenomenon}

If $t_{i}$ is set beyond a reasonable range, abnormal molding phenomenon occurs. E.g. when $t_{i}$ is equal to $2.63 \mathrm{e}-5 \mathrm{~s}$ for $P_{b}=1.0 \mathrm{MPa}$, the balloon parison flies out of the mold core cavity at the end of the first iterative calculation, as shown in Figure 4.

When $t_{i}$ is equal to $2.62 \mathrm{e}-5 \mathrm{~s}$ for $P_{b}=1.0 \mathrm{MPa}$, the balloon parison is still in the mold core cavity at the end of the first iterative calculation, as shown in Figure 5. However, if the iterative calculation continues, the calculation process is interrupted when the time step is smaller than $t_{p}$ which makes the blow molding simulation of balloon unable to continue. Here, $t_{p}$ which causes a similar phenomenon above, is called the boundary value of the iterative time step, $t_{0}$.

\subsection{Analysis of Abnormal Molding Phenomena}

When other technological parameters are fixed, under a given blow molding pressure of balloon, the outward expanding velocity of balloon parison is a constant. According to the linear law, it can be known that the product of the expanding velocity of balloon parison and $t_{i}$ is the expanding distance of balloon parison at the end of the first iteration.

When $t_{i}$ is greater than the boundary value, since the outward expansion distance of balloon parison is greater than the radial size of the mold core cavity at the end of the first iteration, the balloon parison can fly out of the mold core cavity (see Figure 4).

When $t_{i}$ is equal to $t_{0}$, since the outward expansion distance of balloon parison is smaller than the radial size of the mold core cavity at the end of the first iteration, the balloon parison is still in the mold core cavity (see Figure 5). 


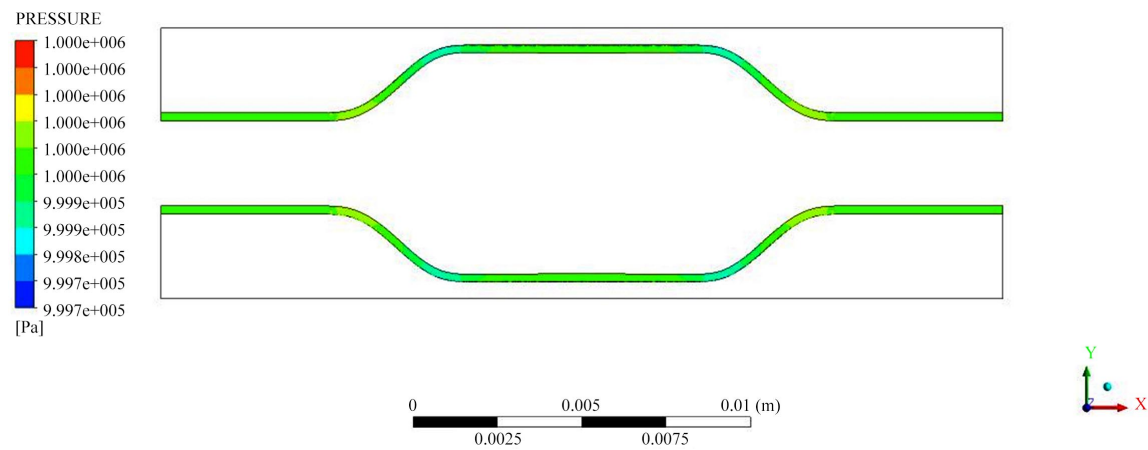

Figure 3. Normal blow molding result of a balloon.

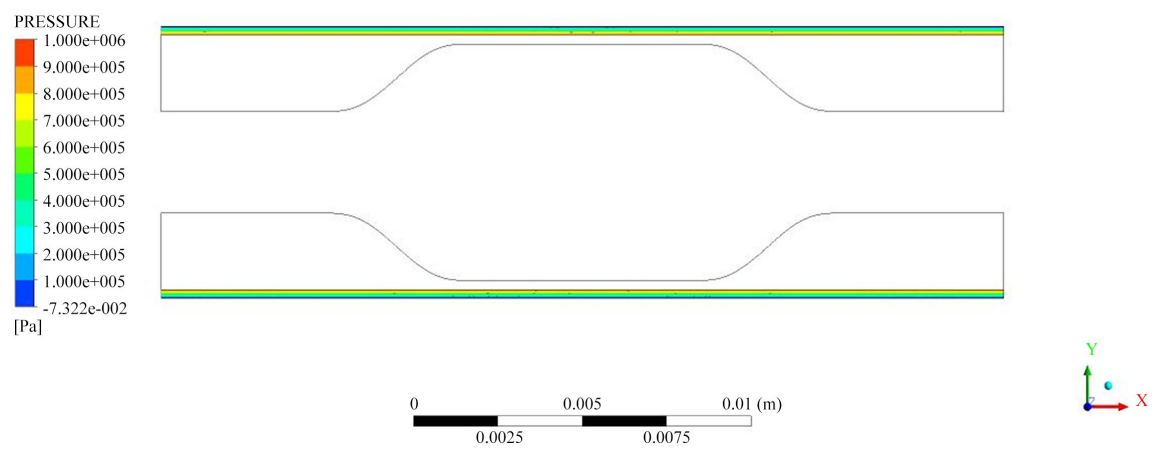

Figure 4. Balloon parison out of the mold core cavity at the end of the first iterative calculation.

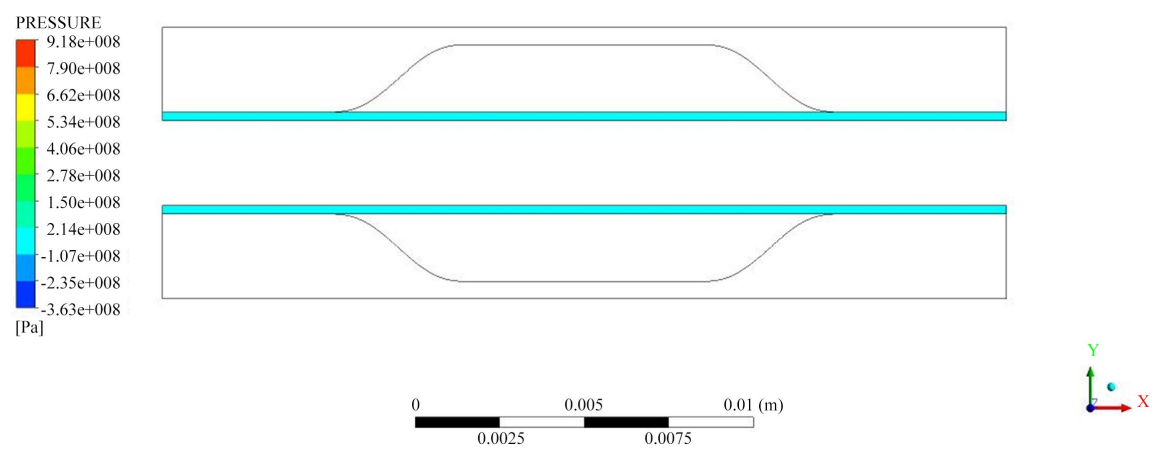

Figure 5. Balloon parison within the mold core cavity at the end of the first iterative calculation.

However, if the iterative calculation continues, the calculation process may be interrupted when the time step is smaller than $t_{i p}$, which makes the blow molding simulation of balloon unable to continue.

In fact, when $t_{i}$ is one order of magnitude smaller than $t_{0}$ in the process of setting software parameters, the iterative calculation of blow molding balloon can proceed smoothly. And the phenomenon that the error is reported when the time step of transient iterative calculation is smaller than $t_{i}$ does not occur.

\subsection{Correlation between $t_{0}$ and $P_{b}$}

Under any given blow molding pressure, a $t_{0}$ can be obtained. In order to obtain 
the relative position relationship between the parison and the mold cavity at the end of the first iteration under different blow molding pressure conditions, the statistics of different given initial values of iterative time step are shown in Table 1. Considering the definition of $t_{0}$ and Table 1 , when the parison still stays in the mold cavity after the first iteration, the corresponding initial value of iterative time step can be considered as $t_{0}$ under the specified blow molding pressure. The graph of these $t_{0}$ with $P_{b}$ is shown in Figure 6. As can be seen from Figure 6, with $P_{b}$ increasing, $t_{0}$ first decreases rapidly and then decreases slowly. In the simulation of blow molding balloon, only when $t_{i}$ is smaller than $t_{0}$, can the transient iteration proceed. It is suggested that $t_{i}$ is one order of magnitude smaller than $t_{0}$ to obtain the result of blow molding balloon.

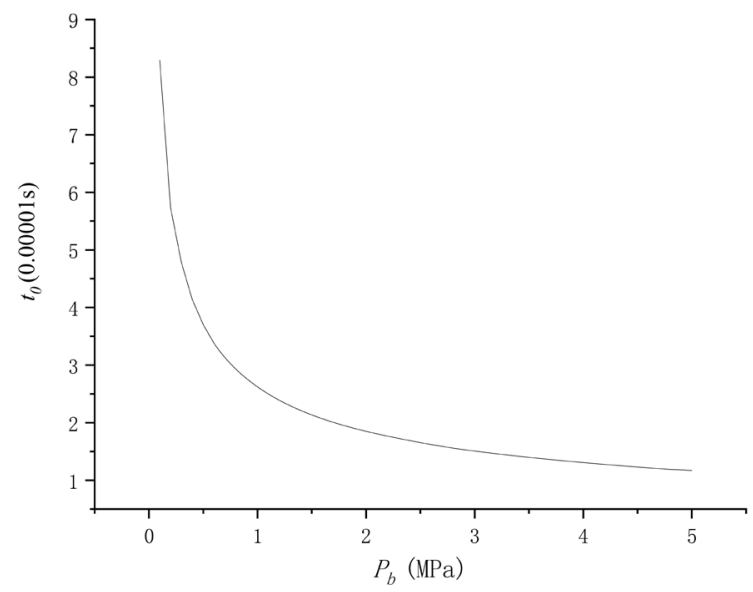

Figure 6. Change of $t_{0}$ with $P_{b}$.

Table 1. Statistics of different given initial values of iterative time step.

\begin{tabular}{|c|c|c|}
\hline $\begin{array}{l}\text { Blow molding } \\
\text { pressure } \\
(\mathrm{MPa})\end{array}$ & $\begin{array}{c}\text { Given initial values of iterative time step } \\
\text { when the parison is inside the cavity after } \\
\text { the first iteration }\left(\times 10^{-5} \mathrm{~s}\right)\end{array}$ & $\begin{array}{c}\text { Given initial values of iterative time step } \\
\text { when the parison is outside the cavity after } \\
\text { the first iteration }\left(\times 10^{-5} \mathrm{~s}\right)\end{array}$ \\
\hline 0.1 & 8.29 & 8.30 \\
\hline 0.2 & 5.73 & 5.74 \\
\hline 0.3 & 4.78 & 4.79 \\
\hline 0.4 & 4.14 & 4.15 \\
\hline 0.5 & 3.70 & 3.71 \\
\hline 0.6 & 3.38 & 3.39 \\
\hline 0.7 & 3.13 & 3.14 \\
\hline 0.8 & 2.93 & 2.94 \\
\hline 0.9 & 2.76 & 2.77 \\
\hline 1.0 & 2.62 & 2.63 \\
\hline 1.1 & 2.50 & 2.51 \\
\hline 1.2 & 2.39 & 2.40 \\
\hline 1.3 & 2.29 & 2.30 \\
\hline
\end{tabular}




\section{Continued}

\begin{tabular}{|c|c|c|}
\hline 1.4 & 2.21 & 2.22 \\
\hline 1.5 & 2.14 & 2.15 \\
\hline 1.6 & 2.07 & 2.08 \\
\hline 1.7 & 2.01 & 2.02 \\
\hline 1.8 & 1.95 & 1.96 \\
\hline 1.9 & 1.90 & 1.91 \\
\hline 2.0 & 1.85 & 1.86 \\
\hline 2.1 & 1.80 & 1.81 \\
\hline 2.2 & 1.76 & 1.77 \\
\hline 2.3 & 1.72 & 1.73 \\
\hline 2.4 & 1.69 & 1.70 \\
\hline 2.5 & 1.65 & 1.66 \\
\hline 2.6 & 1.62 & 1.63 \\
\hline 2.7 & 1.59 & 1.60 \\
\hline 2.8 & 1.56 & 1.57 \\
\hline 2.9 & 1.53 & 1.54 \\
\hline 3.0 & 1.51 & 1.52 \\
\hline 3.1 & 1.48 & 1.49 \\
\hline 3.2 & 1.46 & 1.47 \\
\hline 3.3 & 1.44 & 1.45 \\
\hline 3.4 & 1.42 & 1.43 \\
\hline 3.5 & 1.40 & 1.41 \\
\hline 3.6 & 1.38 & 1.39 \\
\hline 3.7 & 1.36 & 1.37 \\
\hline 3.8 & 1.34 & 1.35 \\
\hline 3.9 & 1.32 & 1.33 \\
\hline 4.0 & 1.31 & 1.32 \\
\hline 4.1 & 1.29 & 1.30 \\
\hline 4.2 & 1.27 & 1.28 \\
\hline 4.3 & 1.26 & 1.27 \\
\hline 4.4 & 1.25 & 1.26 \\
\hline 4.5 & 1.23 & 1.24 \\
\hline 4.6 & 1.22 & 1.23 \\
\hline 4.7 & 1.20 & 1.21 \\
\hline 4.8 & 1.19 & 1.20 \\
\hline 4.9 & 1.18 & 1.19 \\
\hline 5.0 & 1.17 & 1.18 \\
\hline
\end{tabular}




\section{Conclusions}

In this paper, the numerical simulation of a single balloon molding process is studied by POLYFLOW in a mold core cavity with $L=15.0 \mathrm{~mm}$ and $D=7.0$ $\mathrm{mm}$. And the following conclusions are obtained:

1) As $P_{b}$ increases, $t_{0}$ decreases rapidly at first and then slowly. At the end of the first step of iterative calculation for each $t_{0}$, the balloon parison is in the mold core cavity.

2) If $t_{i}$ is smaller than $t_{0}$, the balloon parison is still in the mold core cavity at the end of the first iteration. However, if the iterative calculation continues, the calculation process may be interrupted when the time step is smaller than $t_{0}$, which makes the blow molding simulation of balloon unable to continue.

3 ) It is suggested that $t_{i}$ is one order of magnitude smaller than $t_{0}$ to complete smoothly the simulation of blow molding balloon.

\section{Acknowledgements}

Project Supported by Scientific Research Fund of Chaohu University (KYQD201908)

\section{Conflicts of Interest}

The authors declare no conflicts of interest regarding the publication of this paper.

\section{References}

[1] Fu, X.L. (2007) Study on Numerical Simulation and Process of Balloon Molding. Beijing University of Chemical Technology, Beijing.

[2] Menary, G.H. and Armstrong, C.G. (2006) Experimental Study and Numerical Modeling of Injection Stretch Blow Moulding of Angioplasty Balloons. Plastics Rubber \& Composites, 35, 348-354. https://doi.org/10.1179/174328906X143877

[3] Yang, J.L., Liu, H.S., Huang, X.Y., et al. (2011) Applications of Polyflow Inverse Extrusion Method in the Design of T-Shaped Plastics Profile Extrusion Die. Plastics, 40, 114-117.

[4] Sun, Q.Y. and Qu, X.Y. (2018) Design and Simulation Analysis of Plastic Cast Mould Based on Polyflow. Plastics Science and Technology, 46, 97-101.

[5] Xu, X., Li, B.Q., Jin, M., et al. (2015) Simulation for Pipe Molding Devices with Two Dies Based on Polyflow. China Plastics, 29, 98-101.

[6] Gan, X.H., Cao, J.Y., Yang, C.C., et al. (2010) The Stretch Forming Process of Fiber Based on Polyflow Numerical Simulation. Journal of Donghua University (Natural Science), 36, 271-274.

[7] Gan, X.H., Ma, X.J., Liu, Q., et al. (2011) Numerical Simulation Research of Extrusion-Forming Process of Cross Fibers Based on Polyflow. Journal of Textile Research, 32, 132-136.

[8] Zhao, F., Jia, M.Y., Xue, P., et al. (2011) Die Runners Design of Wpc Construction Wallboard Profiles Based on Polyflow Simulation. Engineering Plastics Application, No. 6, 35-39.

[9] Jiang, W.X., Huang, Z.G., Zhao, Y.L., et al. (2017) Extrusion Analysis of Tian- 
zi-Shaped Tray of Food Based on Polyflow. Food \& Machinery, 33, 86-90.

[10] Zhou, Z.H., Chen, S.K., He, C.L., et al. (2013) Thermoforming Process of Cup Making Machine Based on Polyflow Simulation. Plastics, 42, 96-98, 44.

[11] Zhou, Z.H., Chen, S.K. and He, C.L. (2013) The Shape Optimization for the Cup Making Machine’s Plug Based on Polyflow. China Plastics Industry, 41, 54-58.

[12] Gupta, S., Uday, V., Raghuwanshi, A.S., et al. (2013) Simulation of Blow Molding Using Ansys Polyflow. APCBEE Procedia, 5, 468-473.

https://doi.org/10.1016/j.apcbee.2013.05.079

[13] Suraya, S., Azman, M.D., Fatchurrohman, N., et al. (2016) Simulation on the Effect of Bottle Wall Thickness Distribution using Blow Moulding Technique. IOP Conference Series: Materials Science and Engineering, 114, Article ID: 012004. https://doi.org/10.1088/1757-899X/114/1/012004

[14] https://www.ansys.com/products/fluids/ansys-polyflow 